\title{
NOVEL PEG 4000 DERIVATIVES AND ITS USE IN CONTROLLED RELEASE OF DRUG INDOMETHACIN
}

Lúbia G. Nascimento ${ }^{a}$, Suellen A. Lopes ${ }^{a}$, Ayron B. L. Teodolino ${ }^{a}$, Kátia M. Novacka, Ana Paula M. Barboza ${ }^{b}$, Bernardo R. A. Neves , Maria Luiza S. Azevedo ${ }^{a}$, Lucas R. D. Sousa and Viviane M. R. dos Santos, ${ }^{\mathrm{a}, *}$,

aDepartamento de Química, Instituto de Ciências Exatas e Biológicas, Universidade Federal de Ouro Preto, Campus Morro do Cruzeiro, 35400-000 Ouro Preto - MG, Brasil

bDepartamento de Física, Instituto de Ciências Exatas e Biológicas, Universidade Federal de Ouro Preto, Campus Morro do Cruzeiro, 35400-000 Ouro Preto - MG, Brazil

'Departamento de Física, Universidade Federal de Minas Gerais, 31270-901 Belo Horizonte - MG, Brasil

Recebido em 03/10/2019; aceito em 11/03/2020; publicado na web em 24/04/2020

\begin{abstract}
The insertion of functional groups in polymer compounds may facilitate their interaction with different drugs. PEG polymers are widely used for their low melting point, low toxicity, drug compatibility, and hydrophilicity. They are used as pharmaceutical excipients for the formulation of conventional or modified released drugs and are designed to be upgraded as drug-modulating controllers at specific sites in the body. Indomethacin has been used in the controlled release of drugs because it is a drug that have good interaction with different polymers. The drug is a non-steroidal anti-inflammatory drug used in the treatment of rheumatoid arthritis, osteoarthritis, spondylitis, and other disorders. In this work, PEG 4000 had its chain modified by organic reactions and their derivatives were emulsified to form microparticles using polyvinyl alcohol as an emulsifier. Posteriorly were also incorporated with indomethacin. The samples were characterized to prove the influence of indomethacin on the morphology and thermal behavior of this polymer. The controlled release was performed in the time from 0 to $240 \mathrm{~min}$ using the Ultraviolet Spectroscopy to quantify indomethacin released from the polymer matrix for these 4 hours. Releases over the time were satisfactory as concentrations increased over time, which we can conclude that the structural modification of PEG 4000 was beneficial in the release of the indomethacin drug.
\end{abstract}

Keywords: polyethyleneglycol; indomethacin; incorporation; controlled release.

\section{INTRODUCTION}

The development of polymeric controlled release systems introduced a new concept in drug administration to treat numerous diseases. The purpose of controlled release systems is to maintain an adequate drug concentration in the blood or in target tissues at a desired value as long as possible and, for this, they are able to control the drug release rate. ${ }^{1-3}$ The drug release profile can be programmed to meet specific requirements by optimizing the composition of formulations, processing parameters such as coating level, drug-polymer ratio and type and amount of polymer-plasticizer utilized., ${ }^{4,5}$ The goal for any drug eluting device is to deliver the therapeutic agent of high efficacy at the right time to the desired location with a concentration high enough over a sufficiently long period. Polymeric drugs are polymers with active drugs as part of the main chain that is usually prepared by the association of common drugs for commercial or slightly modified polymers. ${ }^{6-8}$ For a polymer to be used as a system matrix in the controlled release of drugs it must be chemically inert, free from impurities, have an appropriate physical structure, and be easily processed by the organism. ${ }^{8}$ Also important is the decrease of the side effects of certain drugs, especially anti non-steroidal inflammatory, such as indomethacin, which causes irritation to the intestinal mucosa. ${ }^{8}$ The association of polymers in matrix systems has recently shown as an important pharmacotechnical strategy in the search for modulation and prolongation of drug release. These pharmaceutical adjuvants are widely used in formulations intended for the parenteral, topical, rectal oral, as plasticizers, co-solvents or in the preparation of solid dispersions. ${ }^{7}$ In particular, polyethylene glycols (PEG) have been employed for this purpose. The homopolymer PEG 4000 (PEG) used was selected due to its easy processing and appropriate structure that

*e-mail: vivianesantos@ufop.edu.br also has excellent properties, including good solubility in water and organic solvents, lack of toxicity, no antigenicity and therefore no immunogenicity. Furthermore, PEG does not accumulate in the body and displays functional groups for chemical bonding. ${ }^{9,10}$ Polymeric microparticles that comprise microcapsules and microspheres have been proposed as modulators and directs in the controlled release of drugs in specific sites in the organism, as a strategy to mask organoleptic characteristics. ${ }^{11}$ It is also important a decrease of the side effects of certain drugs, especially anti non-steroidal inflammatory, such as indomethacin, which causes irritation to the intestinal mucosa. ${ }^{12}$ Indomethacin (IM) is a non-steroidal anti-inflammatory drug used in the treatment of rheumatoid arthritis, osteoarthritis, alkylation of spondylitis, and other disorders. The oral administration of conventional dosage forms of indomethacin can cause serious gastric and systemic side effects. ${ }^{13}$ A drug delivery system ensures less irritation of the gastrointestinal tract and a lower risk of side effects. In this work, were made reactions to modify the PEG 4000 polymer and the subsequent incorporation of the indomethacin. This study aimed to analyze the chemical modifications in the structure of the PEG chains and their characterization using Thermogravimetry Analysis (TGA), Infrared Spectroscopy (FTIR), Scanning Electron Microscopy (SEM) and Atomic Force Microscopy (AFM) measurements to prove the influence of indomethacin on morphology and thermal behavior of the polymers. For each sample, the controlled release was performed in a total time of $4 \mathrm{~h}$, and the efficiency of the modified structures was verified.

\section{EXPERIMENTAL}

\section{General considerations}

The reagents used for modification chemistry and incorporation of indomethacin were distilled water, Commercial indomethacin, 
Sodium hydroxide $(\mathrm{NaOH})$, acetic anhydride $\left(\mathrm{CH}_{3} \mathrm{COOCOCH}_{3}\right)$, acetic acid $\left(\mathrm{CH}_{3} \mathrm{COOH}\right)$, hydrochloric acid $(\mathrm{HCl})$, sodium bicarbonate $\left(\mathrm{NaHCO}_{3}\right)$, sulfuric acid $\left(\mathrm{H}_{2} \mathrm{SO}_{4}\right)$ and dichloromethane $\left(\mathrm{CH}_{2} \mathrm{Cl}_{2}\right)$ were purchased from Vetec. Ethyl iodide $\left(\mathrm{CH}_{3} \mathrm{CH}_{2} \mathrm{I}\right)$, poly (vinyl alcohol) (PVA), and polyethylene glycol 4000 (PEG 4000) were purchased from Sigma-Aldrich.

\section{Synthesis of PEG 4000 derivatives ${ }^{14-16}$}

PEG 4000 was subjected to 4 types of chemical modifications in order to functional groups inserted in its polymer chain facilitate the process of incorporation of indomethacin and, consequently, its release (Figure 1).<smiles>CC(=O)OCCOCCO</smiles>

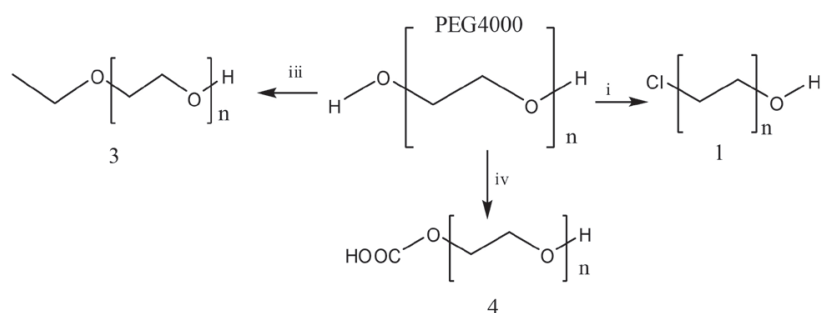

4

Polymer $1: \mathrm{i}=\mathrm{HCl} /$ reflux $/ \mathrm{NaHCO}_{3}$ (aq); (PEG 4000 HALOG) Polymer 2: ii $=\mathrm{CH}_{3} \mathrm{CO}_{2} \mathrm{H} /\left(\mathrm{CH}_{3} \mathrm{CO}\right)_{2} \mathrm{CO}$; (PEG $\left.4000 \mathrm{ACET}\right)$ Polymer 3: iii $=\mathrm{CH}_{3} \mathrm{CH}_{2} \mathrm{I} / \mathrm{NaOH}(\mathrm{aq}) / \mathrm{T}=40^{\circ} \mathrm{C} ;$ (PEG $4000 \mathrm{ETIL}$ ) Polymer 4: iv $=\mathrm{CH}_{3} \mathrm{CO}_{2} \mathrm{H}_{2} / \mathrm{H}_{2} \mathrm{SO}_{4}$ /refluxo; (PEG $\left.4000 \mathrm{HIDROL}\right)$

Figure 1. The general reaction to the synthesis of modified PEG4000

Synthesis 1: Halogenation of PEG 4000 (Polymer 1)

In a round bottom flask we added $2 \mathrm{~g}$ of PEG 4000 and solubilized in $10 \mathrm{~mL}$ of $\mathrm{CH}_{2} \mathrm{Cl}_{2}$, and then we added $0.50 \mathrm{~mL}$ of $\mathrm{HCl}$. The reaction mixture was maintained in reflux for $40 \mathrm{~min}$, and after the reaction, the mixture was placed in a separatory funnel. When the phase separation finalized, we added $5 \mathrm{~mL}$ of $5 \% \mathrm{NaHCO}_{3}$. The organic phase was collected, and after solvent evaporation in a stove for $40^{\circ} \mathrm{C}$ was obtained $0.87 \mathrm{~g}$ of a dry and white solid.

\section{Synthesis 2: Acetylation of PEG 4000 (Polymer 2)}

In a round bottom flask, we added $2 \mathrm{~g}$ of PEG 4000, in which we solubilized in $10.00 \mathrm{~mL}$ of $\mathrm{CH}_{2} \mathrm{Cl}_{2}$. In another beaker was prepared a solution of $5.00 \mathrm{~mL}$ of acetic anhydride with $5.00 \mathrm{~mL}$ of acetic acid. This solution was added to the flask containing the PEG 4000. The reaction mixture was maintained at a temperature of $40{ }^{\circ} \mathrm{C}$ for 30 min. Upon completion of the reaction, the mixture was poured into a beaker with $100.00 \mathrm{~mL}$ of ice water. The modified PEG 4000 solidified and was separated by simple filtration. After complete solvent evaporation in a stove for $40{ }^{\circ} \mathrm{C}$ was obtained $1.00 \mathrm{~g}$ of a dry and white film.

\section{Synthesis 3: Ethylation of PEG (Polymer 3)}

In a round bottom flask we added $2 \mathrm{~g}$ of PEG 4000, and it was solubilized in $10.00 \mathrm{~mL}$ of $\mathrm{CH}_{2} \mathrm{Cl}_{2}$. Then we added $10 \mathrm{~mL}$ of $10 \%$ $\mathrm{NaOH}$ solution. The reaction mixture was heated in an oil bath with magnetic stirring for $45 \mathrm{~min}$. We added $2.4 \mathrm{~mL}$ of $\mathrm{CH}_{3} \mathrm{CH}_{2} \mathrm{I}$, and the reaction mixture was maintained at a temperature of $40{ }^{\circ} \mathrm{C}$ for 4 hours. After the reaction, the mixture was transferred to a separatory funnel, and it was added $10 \mathrm{~mL}$ of water, $20.00 \mathrm{~mL}$ of $\mathrm{CH}_{2} \mathrm{Cl}_{2}$ and a saturated $\mathrm{NaCl}$ solution for phase separation. The organic phase was collected and was dried with anhydrous $\mathrm{MgSO}_{4}$. The organic phase was filtered, and after complete solvent evaporation in a stove for $40^{\circ} \mathrm{C}$ it was obtained $0.50 \mathrm{~g}$ of a dry and white film.

\section{Synthesis 3: Esterification Followed by Hydrolysis of PEG 4000 (Polymer 4)}

In a round bottom flask we added $2 \mathrm{~g}$ of PEG 4000, and it was solubilized in $10.00 \mathrm{~mL}$ of $\mathrm{CH}_{2} \mathrm{Cl}_{2}$. In a beaker we prepared a mixture with $0.1 \mathrm{~mL}$ of concentrated $\mathrm{H}_{2} \mathrm{SO}_{4}$ and $7.00 \mathrm{~mL}$ of $\mathrm{CH}_{3} \mathrm{COOH}$. This mixture was added to a round bottom flask containing the PEG400 solubilized. The reaction mixture was maintained at a temperature of $40{ }^{\circ} \mathrm{C}$ for $65 \mathrm{~min}$. After cooling it was added $10 \mathrm{~mL}$ of water. The organic phase was collected and was dried with anhydrous $\mathrm{MgSO}_{4}$. The organic phase was filtered, and after complete solvent evaporation in a stove for $40{ }^{\circ} \mathrm{C}$, it was obtained $1.50 \mathrm{~g}$ of a dry and white film.

\section{Method of incorporation of PEG 4000 and derivatives incorporated with indomethacin ${ }^{16,17}$}

The incorporation was realized in two phases:

Aqueous phase: A beaker containing $40.0 \mathrm{~mL}$ of water was warmed in a heating plate.

When the temperature reached approximately $70{ }^{\circ} \mathrm{C}, 0.12 \mathrm{~g}$ of poly (vinyl alcohol) was added, stirring slowly until complete dissolution.

Organic phase: In another heater plate, it was placed another beaker with $6.00 \mathrm{~mL}$ of dichloromethane $\left(\mathrm{CH}_{2} \mathrm{Cl}_{2}\right)$. This solvent solubilized the $0.30 \mathrm{~g}$ of PEG 4000 and derivatives and $0.10 \mathrm{~g}$ of indomethacin at a temperature of $40{ }^{\circ} \mathrm{C}$. The aqueous phase was poured into the organic phase after the preparation of the two phases. The mixture was subjected to the agitation of $500 \mathrm{rpm}$, for $4 \mathrm{~h}$ at a temperature of $35^{\circ} \mathrm{C}$. During this process, small portions $(1000 \mathrm{~mL})$ of dichloromethane were added. Then the products were taken to a stove at $40{ }^{\circ} \mathrm{C}$ for $24 \mathrm{~h}$ to evaporate the dichloromethane. After this time, we obtained solids polymers with varied yields. In the sequence of the indomethacin's incorporation, the samples were cited with "INCORP INDOM" after their names for identification.

The efficiency of incorporation of the copolymer with indomethacin was estimated from mass (polymer+indomethacin+PVA) before and after the liberation of indomethacin using the Equation $1 .{ }^{17}$ After the a incorporation the polymer wih indomethacin was dissolved in Ethanol and only the indomethacin presented solubilization in Ethanol.

$$
\% \text { Incorporation Efficiency }=\mathrm{W}_{\mathrm{I}} \div \mathrm{W}_{\mathrm{T}} \times 100
$$

where $\mathrm{W}_{\mathrm{T}}$ (Wtotal) are the masses of the polymer, PVA and indomethacin, respectively.

$\mathrm{W}_{\mathrm{I}}$ (WIndomethacin) is mass of the dry indomethacin after the liberation and evaporation of the solvent.

\section{Solubility test}

For the solubility test, $0.1 \mathrm{~g}$ of the PEG 4000, PEG 4000 ETIL, PEG 4000 ACET, PEG 4000 HIDROL, PEG 4000 HALOG, PEG 4000 INCORP INDOM, PEG 4000 ETIL INCORP INDOM, PEG 4000 ACET INCORP INDOM, PEG 4000 HIDROL INCORP INDOM, PEG 4000 HALOG INCORP INDOM were dissolved in $3.0 \mathrm{~mL}$ of solvent under agitation for $30 \mathrm{~min}$ in the room temperature and hot. The used solvents were ethanol, dimethylsulfoxide, acetone, chloroform, dichloromethane, and hexane.

\section{In vitro controlled release study of the indomethacin ${ }^{16}$}

The concentration used for the release was $0.05 \mathrm{mg} \mathrm{mL}^{-1}$. It was 
weighed $1.25 \mathrm{mg}$ of each PEG 4000 incorporated to prepare the buffer solution with $25.0 \mathrm{~mL}$ of $\mathrm{pH}$ 7.2. Every $15 \mathrm{~min}$, an aliquot of the solution was evaluated on the ultraviolet spectrophotometer at a wavelength of $320 \mathrm{~nm}$, starting from 0 (zero) to at most $240 \mathrm{~min}$.

\section{Characterizations}

Scanning Electron Microscopy (SEM): The SEM analyses were performed on a JEOL equipment, JSM6510, and the sample preparation was done in a Quorum evaporator. The analysis of the samples was done to the surface, and it was coated with carbon.

Atomic Force Microscopy (AFM): The AFM characterization was carried out on a BrukerMultiMode 8 SPM, using the Peak Force Quantitative NanoMechanical imaging mode ${ }^{\circledR}$. Si cantilevers (from Bruker), with spring constants of $0.4-0.8 \mathrm{~N} \mathrm{~m}^{-1}$ and a tip radius of curvature $\sim 10 \mathrm{~nm}$, were used throughout the study for sample imaging. All AFM images were processed (leveling, profiling and $3 \mathrm{D}$ rendering) using the software from Bruker.

Thermogravimetric (TGA): The analysis were evaluated by thermogravimetric equipment on a T.A. Instruments Model SDT 2960 Simultaneous DTA-TGA using a heating rate of $20^{\circ} \mathrm{C} \mathrm{min}^{-1}$, a temperature range of $20-700{ }^{\circ} \mathrm{C}$ and usually done in an inert atmosphere.

Fourier-Transform Infrared Spectroscopy (FTIR): The spectra were obtained using the equipment Thermo Scientific Nicolet 380 FT-IR, in the range of wave number between 500 and $4000 \mathrm{~cm}^{-1}$. The spectra were normalized, and the main vibration bands were associated with chemical groups. These spectra were reproduced through the Horizon program.

UV/VIS spectroscopy: The analysis of in vitro Controlled Release of the indomethacin were realized using UV/VIS spectroscopy equipment. Instruments Model FEMTO800Xi. The evaluated of the release on the ultraviolet spectrophotometer was made in the wavelength $320 \mathrm{~nm}$ with Quartz bucket and the blank used was the buffer solution $\mathrm{pH} 7.2$.

\section{RESULTS AND DISCUSSION}

\section{PEG 4000 and derivatives incorporated with indomethacin}

The chemistry modification of PEG 4000 and the incorporations of the PEG 4000 and their derivatives with indomethacin were efficient. The products obtained presented yields between $25 \%$ and $75 \%$. The yield of the PEG 4000 and its derivatives obtained in the incorporation of the indomethacin were between $50 \%$ and $90 \%$. The PEG 4000 and its derivatives, which were not incorporated, were only soluble in dichloromethane solvent. The PEGs incorporated with indomethacin were soluble in chloroform and dichloromethane. After the modifications at the PEG chain, one could observe the formation of a homogeneous film in the PEG 4000 ACET and PEG 4000 HALOG, and a heterogeneous film in the PEG 4000 HIDROL, differently from what was observed in the PEG 4000 ETIL, which was one aspect of dust. The physical aspect of embedded copolymers is shown in Figure 2. These macroscopic physical aspects represented in Figure 2, indicate that the PEG modification was efficient since it has same morphological characteristics.

Table 1 shows the incorporation efficiency of each polymer. The PEG 4000 ACET INCORP INDOM presented was higher value of efficiency to incorporation, due present stronger interaction of chemicals functions of the polymer with the indomethacin. The PEG 4000 ETIL INCORP INDOM presented low interaction with drug.

\section{Characterizations}

\section{SEM Analysis of PEG 4000 and derivatives incorporated with indomethacin}

According to the photomicrographs, it is possible to notice that indomethacin has morphology in the form of crystals. In Figure 3, one can see that in the polymers, PEG 4000 and derivatives PEG 4000, without incorporations, the formation of microspheres was not effective. After the incorporation, it is possible to notice
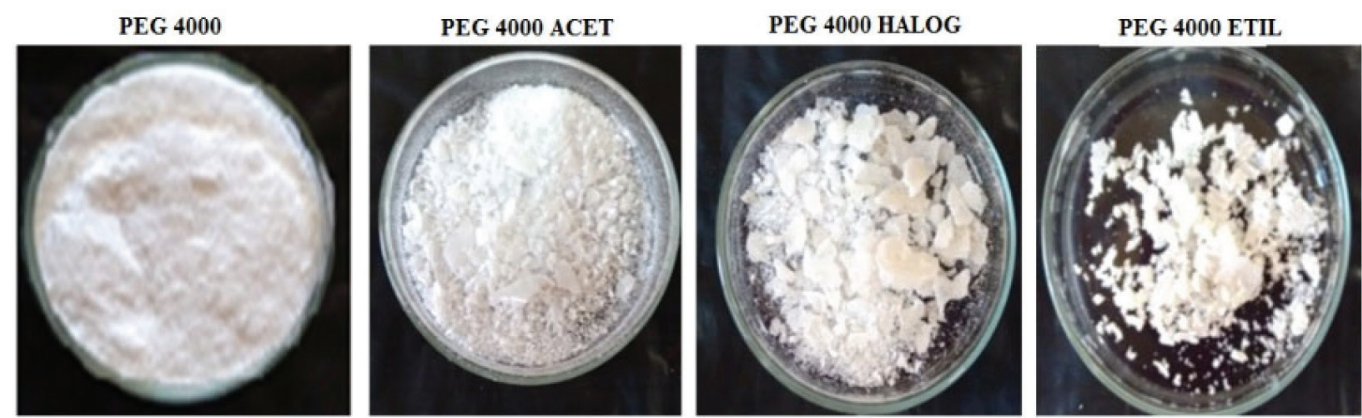

PEG 4000

INCORP INDOM

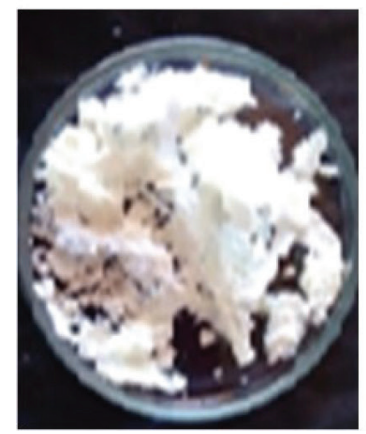

PEG 4000 ACET INCORP INDOM

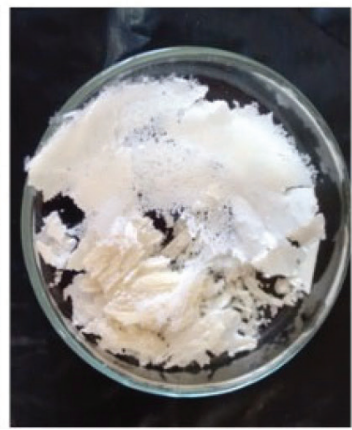

PEG 4000 HALOG INCORP INDOM

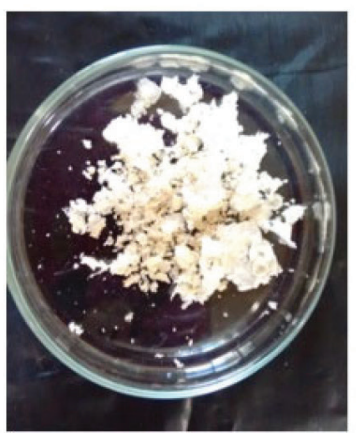

PEG 4000 ETIL INCORP INDOM
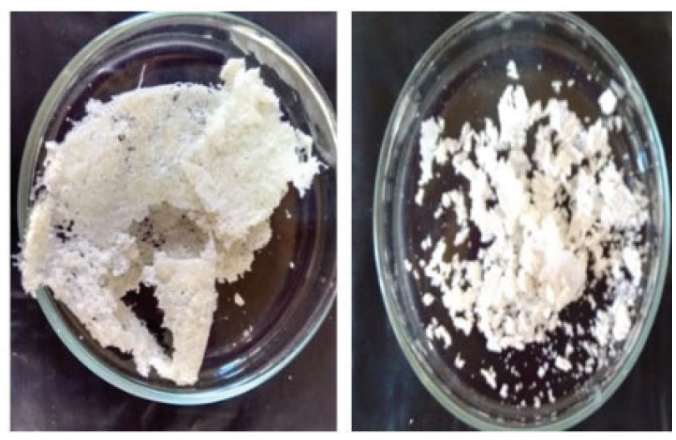

Figure 2. Physical aspects of the PEG4000, derivatives of PEG 4000, incorporated with indomethacin 
Table 1. Pratical efficiency for incorporation of the copolymer with indomethacin

\begin{tabular}{lcc}
\hline Polymer with indomethacin & $\begin{array}{c}\text { Mass } \\
\text { obtained }(\mathrm{g})\end{array}$ & $\begin{array}{c}\text { Efficiency of } \\
\text { incorporation }(\%)\end{array}$ \\
\hline PEG 4000 INCORP INDOM & 0.0121 & 76.36 \\
PEG 4000 ACET INCORP INDOM & 0.0167 & 97.14 \\
PEG 4000 HIDROL INCORP INDOM & 0.0150 & 93.30 \\
PEG 4000 ETIL INCORP INDOM & 0.0116 & 66.95 \\
PEG 4000 HALOG INCORP INDOM & 0.0147 & 91.98 \\
\hline
\end{tabular}

small and large spheres formed in the incorporated polymers. The incorporation process of the PEG 4000 INCORP INDOM, PEG 4000 ACET INCORP INDOM and PEG 4000 ETIL INCORP INDOM polymers intensified the formation of the microspheres, suggesting the possibility of greater efficiency in the incorporation process with the PEG 4000 INCORP INDOM and with the ethyl group present in the chains of the polymer PEG 4000 ETIL INCORP INDOM. In two incorporated polymers PEG 4000 ACET INCORP INDOM and PEG 4000 ETIL INCORP INDOM, and in the polymer PEG 4000 INCORP INDOM, there was visible the incorporation of indomethacin, as evidenced by the presence of crystals of the drug, even though they presented differentiated photomicrographs from the other modified polymers.

\section{AFM Analysis of PEG 4000 and derivatives incorporated with indomethacin}

Samples for AFM analysis were prepared by the spread coating method ${ }^{15}$ using $0.7 \mathrm{mg} \mathrm{mL}^{-1}$ of dichloromethane solution on mica substrate and dried after $30 \mathrm{~s}$ by nitrogen flux. Figure 4 shows the observed results. In (a) PEG 4000, (b) PEG 4000 INCORP INDOM, (c) PEG 4000 HIDROL, (d) PEG 4000 HIDROL INCORP INDOM, (e) PEG 4000 ACET, (f) PEG 4000 ACET INCORP INDOM, (g) PEG 4000 HALOG, (h) PEG 4000 HALOG INCORP INDOM, (i) PEG 4000 ETIL, (j) PEG 4000 ETIL INCORP INDOM. In all cases,
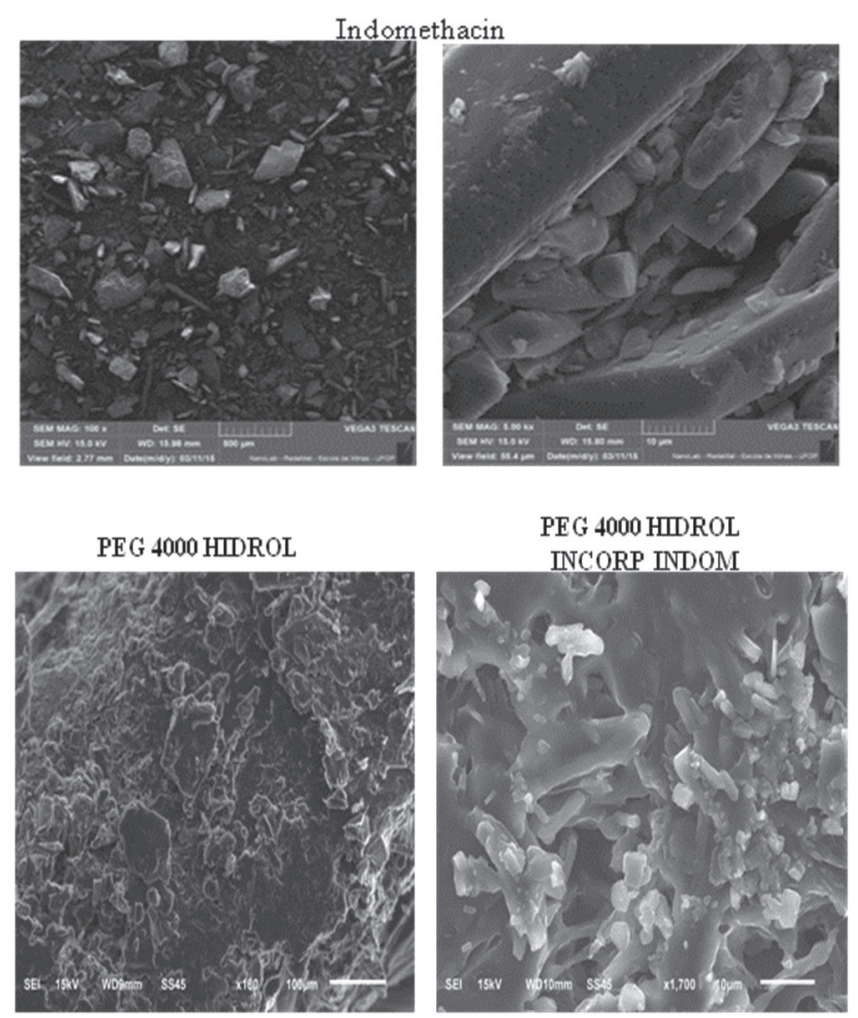

PEG 4000ACET

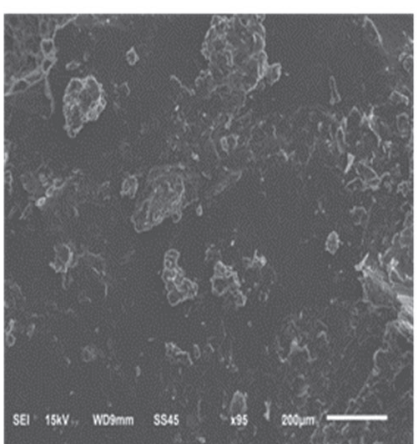

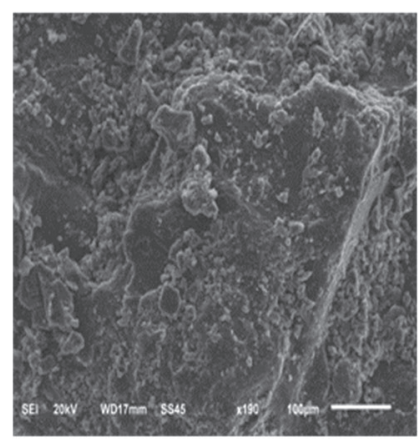

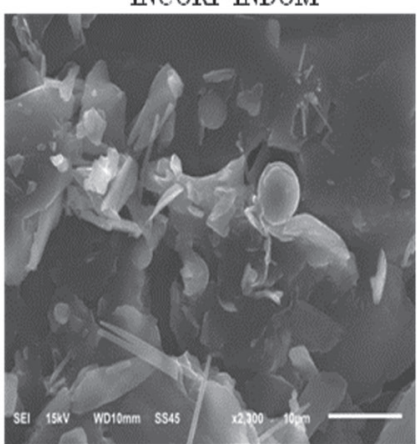

PFG 4000

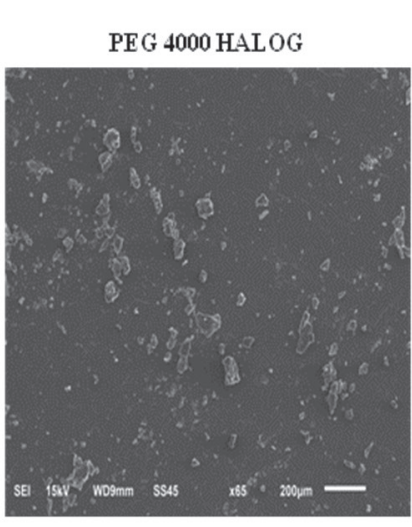

PEG 4000 ETII INCORPINDOM

PFG 4000 INCORP INDOM

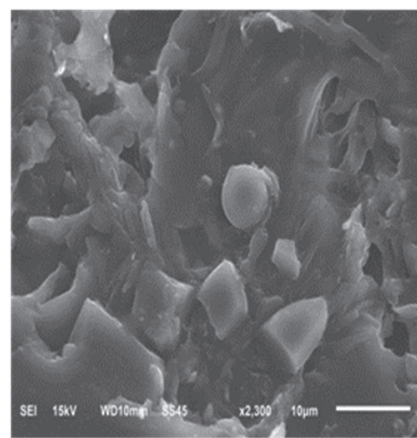

PEG 4000 HALOG INCORP INDOM

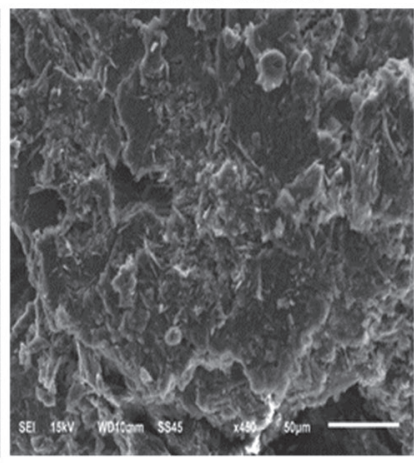

PEG 4000ETII
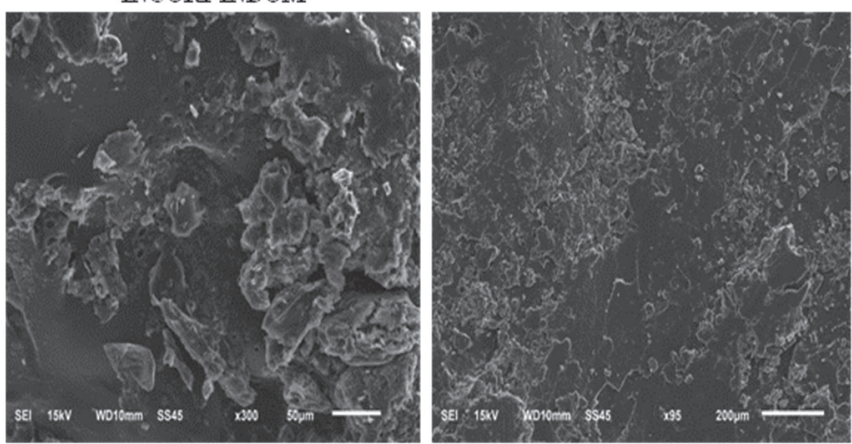

Figure 3. Formation of the microspheres of PEG4000, derivatives of PEG 4000, PEG4000 incorporated with indomethacin and derivatives PEG 4000 incorporated with indomethacin 

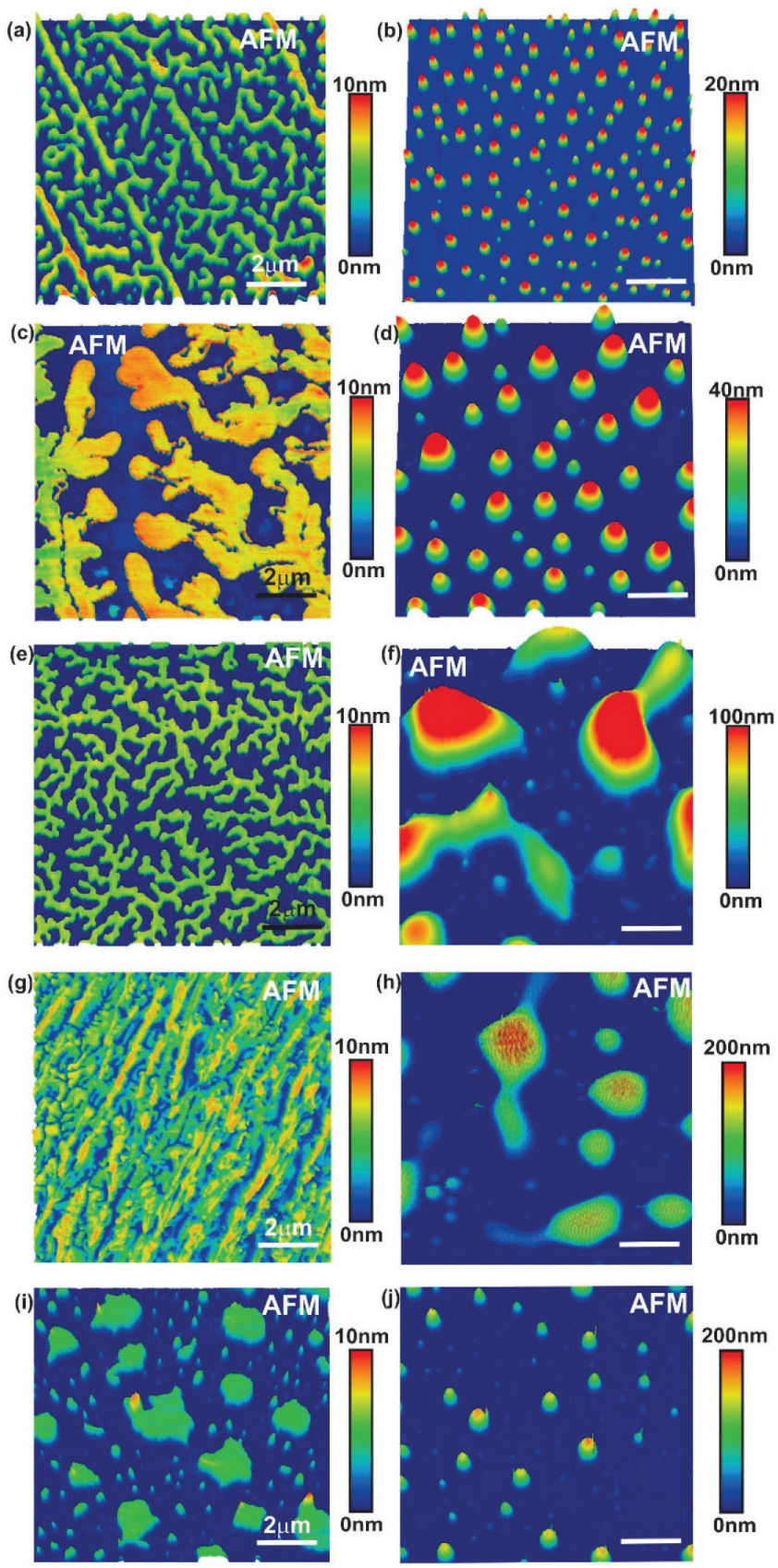

Figure 4. AFM images of PEG4000 thin films before (a, $c, e, g$ and i) and after incorporation process $(b, d, f, h$ and $j)$

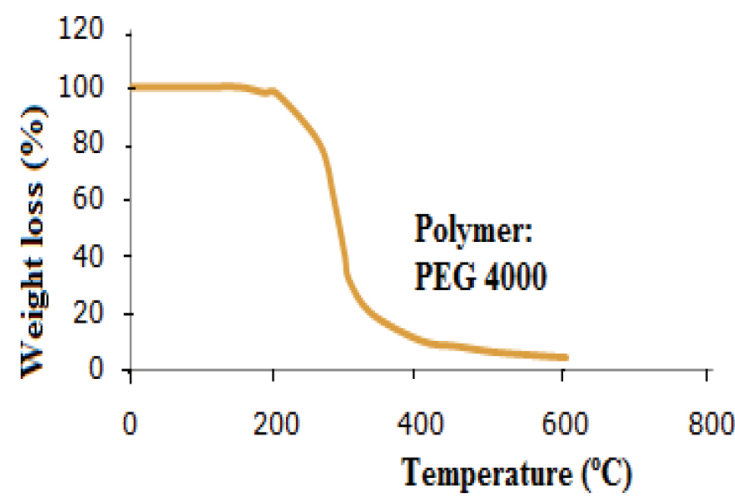

considerable changes in the film organization can be seen, produced by a modification of the polymer chain and by incorporation process.

\section{TG Analysis of PEG 4000 and derivatives incorporated with indomethacin}

This technique also confirmed that PEG incorporated with indomethacin. Their pure derivatives and derivatives of PEG incorporated with indomethacin have been modified due to the variation curves of weight loss from $200{ }^{\circ} \mathrm{C}$ to $400{ }^{\circ} \mathrm{C}$ (Figures 5 and 6).

It is possible to observe the decrease of the initial degradation temperature of the incorporated polymers with indomethacin samples in approximately $200^{\circ} \mathrm{C}$. The insertion of the ethyl group (Polymer 3) by alkylation reaction changes the initial degradation temperature of PEG to about $350{ }^{\circ} \mathrm{C}$, as shown in Figure 6 .

\section{FTIR Analysis of PEG 4000 and derivatives incorporated with indomethacin}

Through the IR spectroscopy technique, it was observed that all derivatives of PEG show the absorption band related to the $\mathrm{C}-\mathrm{OH}$ bond at approximately $3500 \mathrm{~cm}^{-1}$, equal to PEG 4000 in this absorption band, but with different intensities. In PEG 4000 HALOG one could observe a significant reduction of the $\mathrm{C}-\mathrm{OH}$ band at $3500 \mathrm{~cm}^{-1}$ indicating the conversion of the $\mathrm{OH}$ group of $\mathrm{Cl}$, and finally, the presence of bands $700 \mathrm{~cm}^{-1}$ characteristics of $\mathrm{C}-\mathrm{Cl}$, confirming a halogenating success. PEG 4000 ACET showed that a band of $\mathrm{C}-\mathrm{OH}$ decreased related to $\mathrm{C}-\mathrm{OH}$ band of pure PEG 4000, by being converted to anacetyl group. In addition, there was the emergence of the band $1735 \mathrm{~cm}^{-1}$, characteristic of ester carbonyl $\left(\mathrm{C}-\mathrm{O}-\mathrm{C}=\mathrm{O}\right.$ ) and the band $1225 \mathrm{~cm}^{-1}$ related to C-O-C stretch of the ester functional group. PEG 4000 HIDROL showed a wide band of $\mathrm{C}-\mathrm{OH}$ featuring the carboxylic acid of structure and the presence of an absorption band at about $1700 \mathrm{~cm}^{-1}$, referring to $\mathrm{C}=\mathrm{O}$ of carbonylic acid. In the PEG 4000 ETIL, there was a decrease in the absorption band due to $\mathrm{OH}$ and the substitution of the hydroxyl $(\mathrm{OH})$ by ethoxy $\left(\mathrm{O}-\mathrm{CH}_{2} \mathrm{CH}_{3}\right)$ resulting in two absorption bands in $1200 \mathrm{~cm}^{-1}$ to the C-O-C ether group and in 1300 and $1400 \mathrm{~cm}^{-1}$ due to the presence of $\mathrm{CH}_{2}$ and $\mathrm{CH}_{3}$. By distinct bands of absorptions on links $\mathrm{C}-\mathrm{OH}$ and $\mathrm{C}=\mathrm{O}$ values, it is possible to notice the chemical modification of the PEG 4000 after the insertion of various groups in their chains (Figure 7).

In the incorporated polymers, PEG 4000 and derivatives it was possible to notice the modification caused by the insertion of the drug, and the appearance of the specific bands of indomethacin: carboxylic acid, $\mathrm{OH}$ wide band in range $2500-3400 \mathrm{~cm}^{-1}$, band $\mathrm{C}=\mathrm{O}$ of carboxylic acid at $1700 \mathrm{~cm}^{-1}$, band $\mathrm{C}=\mathrm{O}$ of amide at $1687 \mathrm{~cm}^{-1}$, characteristic band of aromatic $\mathrm{CN}$ at $1369 \mathrm{~cm}^{-1}$, tri-substituted aromatic ring bands at

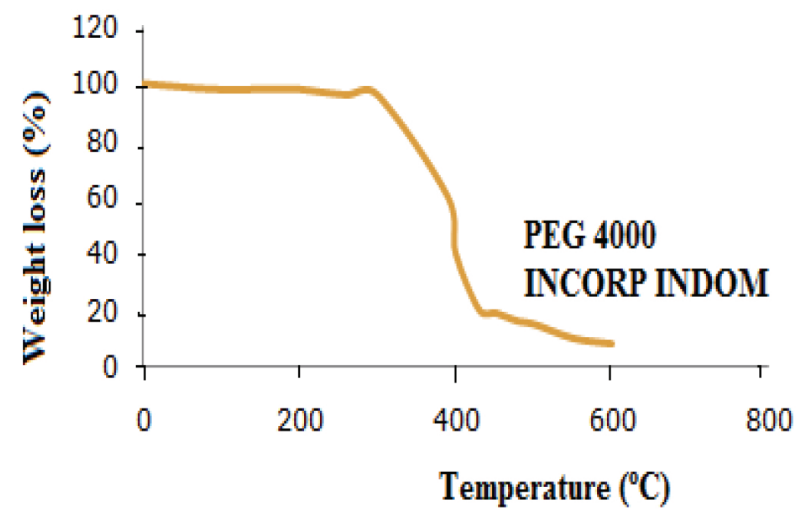

Figure 5. TG curves of PEG 4000 and PEG 4000 incorporated with indomethacin 

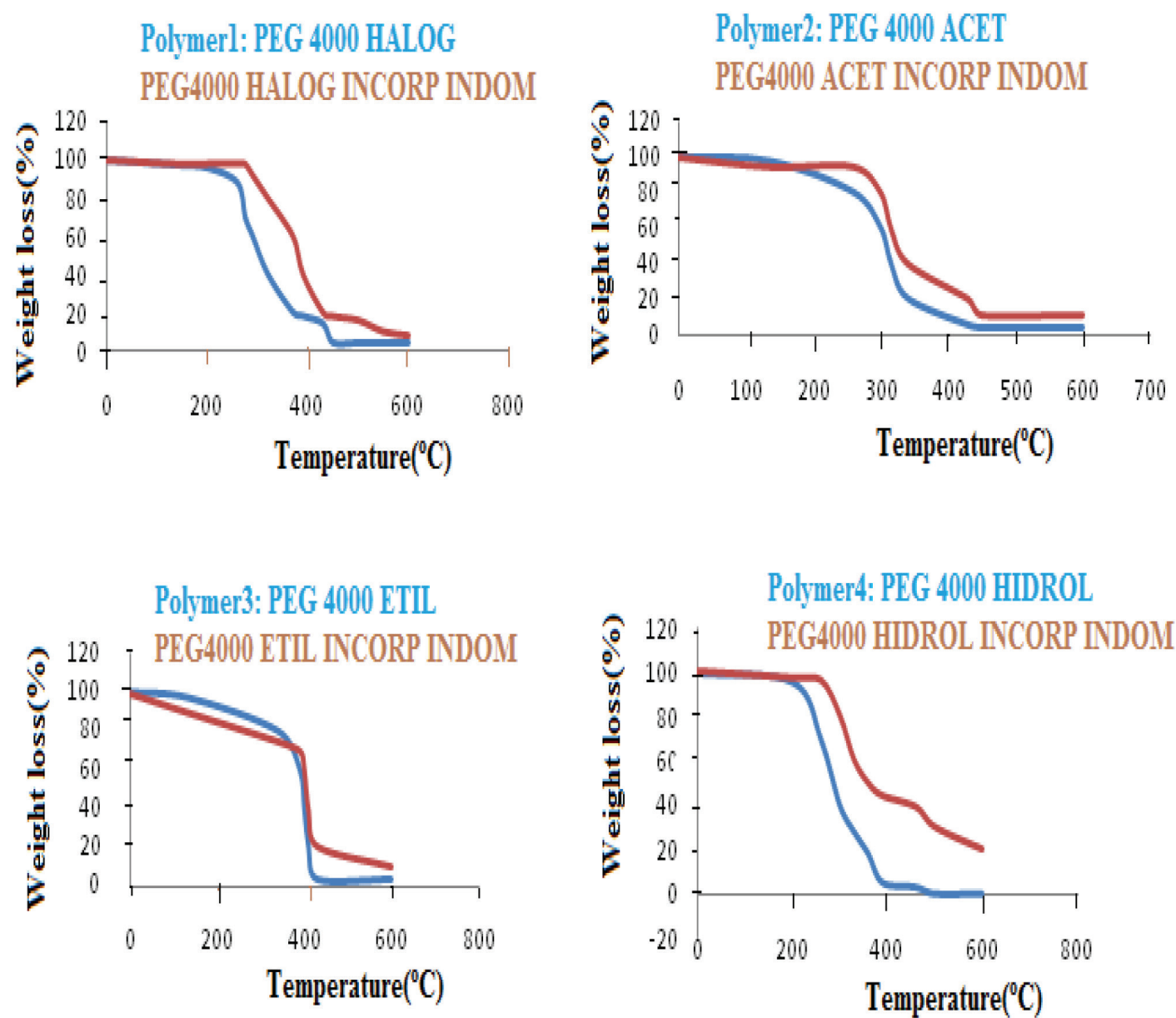

Figure 6. TG curves of PEG 4000 derivatives and PEG 4000 derivatives incorporated with indomethacin

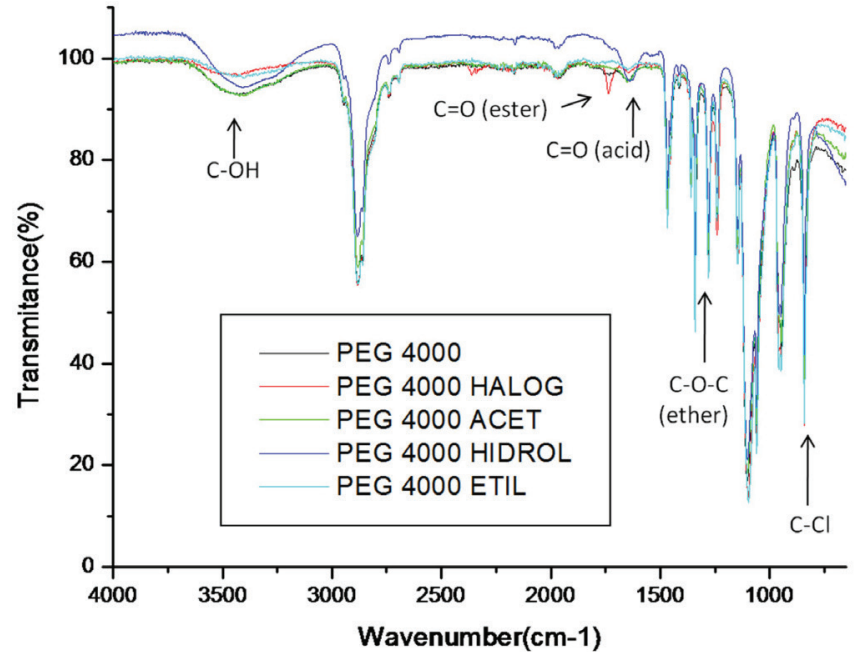

Figure 7. IR spectroscopy of the PEG and derivatives

837 and $753 \mathrm{~cm}^{-1}$. The presence of characteristic bands intrinsic to the PEG 4000 and derivatives is also observed at $2882 \mathrm{~cm}^{-1}$, referring to C-H of aliphatic, in $1470 \mathrm{~cm}^{-1}$, and characteristic of the band of $\mathrm{CH}_{2}$ and in $1369 \mathrm{~cm}^{-1}$ referring to the presence of $\mathrm{CH}_{3}$. One can observe that the modified polymers have bands referring to both the starting polymer and the drug. There is also a change in the spectrum profile related to the starting polymer, which is related to the modifications performed. It is possible to notice an $\mathrm{OH}$ broad band, due to the incorporation with the indomethacin, which also presents hydroxyl of the carboxyl group in the structure (Figure 8).

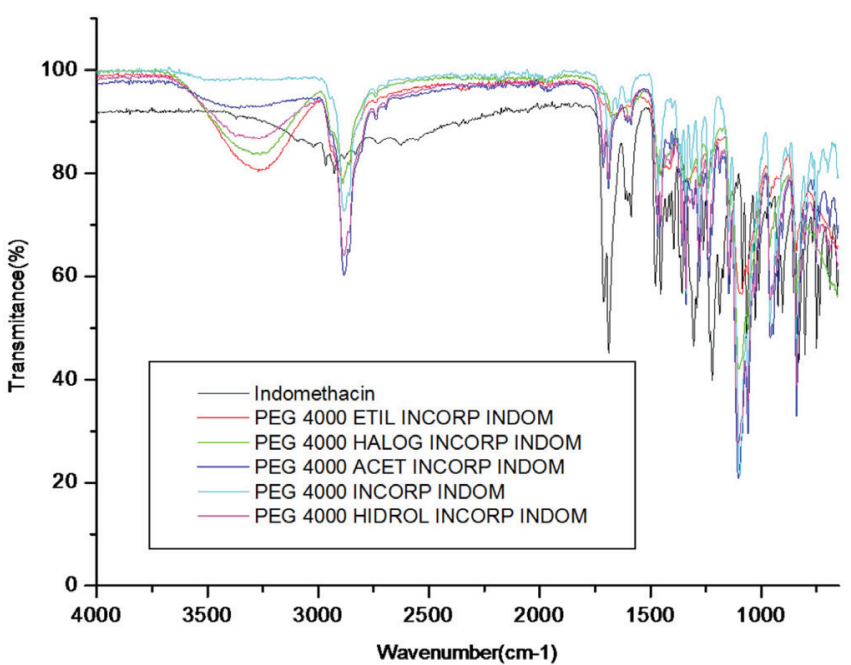

Figure 8. IR spectroscopy of the PEG and derivatives incorporated with indomethacin

\section{Controlled Release of the indomethacin}

Drug release profile is directly correlated with drug-polymer interaction. There has to be an interaction, but it cannot be very strong as it is possible that the drug will not be released. Among the various properties of polymers, some are most important when designing a drug delivery system, such as permeability, surface properties such as hydrophilicity, lubrication, smoothness, surface energy, adhesion, solubility and glass transition temperature. Depending on the release mechanism, the $\mathrm{pH}$ of the polymer may also be an important 
property. When the drug must be released at a specific pH (i.e., in the gastrointestinal tract or colon), nonionic polymers cannot be used because they are $\mathrm{pH}$ independent. In other applications, the most uniform release of the drug is throughout the gastrointestinal tract, which has different $\mathrm{pH}$ values depending on location, is favored. ${ }^{18}$

After the characterization of the samples, the controlled release study was carried out. First, the origin polymer was released, that is, without the modification in the chain and incorporated with indomethacin, as shown in Figure 9. It is possible to notice that the polymer obtained a low initial release, and mainly, its curve did not show maintenance of the linearity within the time studied. The PEG 4000 INCORP INDOM presented microspheres, but it did not liberate the indomethacin due to a larger interaction.

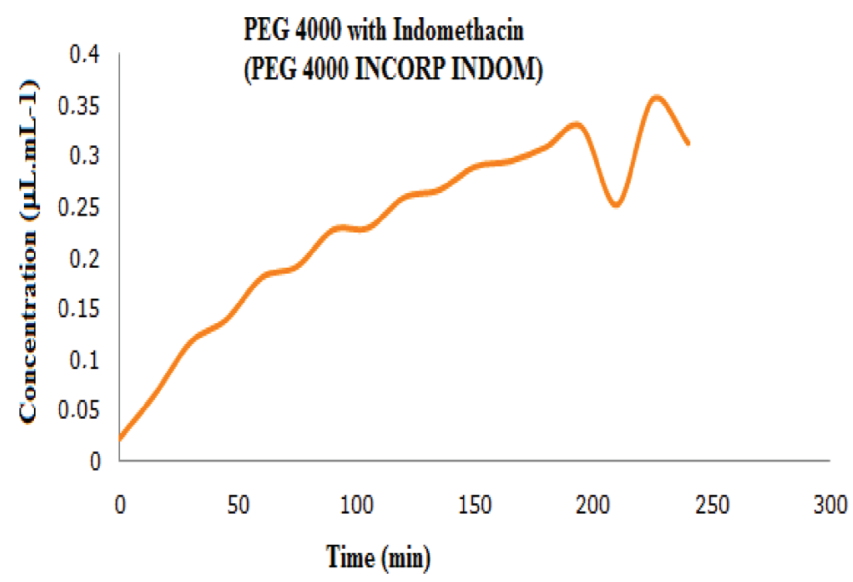

Figure 9. PEG4000 release curve incorporated with indomethacin at $p H 7.2$ for two hours

In Figure 10, one can observe how the modification reaction improved the profile release of the polymer. It seems that all the incorporated derivatives of PEG 4000 are suitable for the release of this drug by the fact of releasing indomethacin constantly over time, and with this, to quickly exert its function which is to alleviate pain, fever, and inflammation. However, the PEG 4000 ACET INCORP INDOM and PEG 4000 HIDROL INCORP INDOM derivatives showed a better release constancy profile. The PEG 4000 ACET INCORP INDOMET maintained the linearity after the first hour and a greater initial release, while PEG 4000 HIDROL INCORP INDOMET maintained linearity after the second hour and still in a lower concentration in relation to the acetylated. The PEG 4000 ETIL INCORP INDOM and PEG 4000 HALOG INDOM INCORP derivatives have their indomethacin concentration increased at the end of the release. It is necessary to extend the release time in these cases.

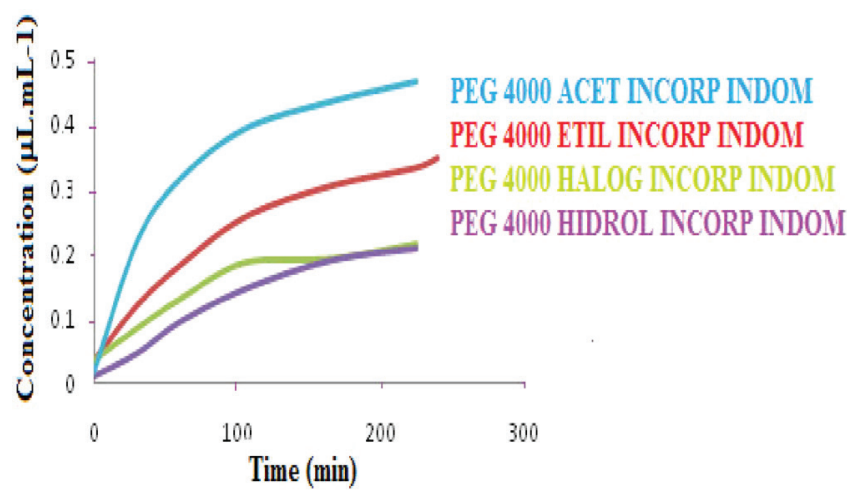

Figure 10. PEG4000 derivatives incorporated with indomethacin releases curves at $\mathrm{pH} 7.2$ for two hours

\section{CONCLUSION}

The characterization techniques employed were enough to confirm the presence of functional groups in the inserted PEG 4000 and their derivatives. By the TGA curves, it was possible to notice a change in the thermal behavior of the homopolymer after the insertion of organic functional groups of high, low and medium polarity on the polymer chain. The reduction of the initial degradation temperature of the modified samples is proof of the efficiency of the reaction for modifying the PEG chain. In the infrared spectra it was possible to see that all derivatives of PEG showed the absorption band at $3,500 \mathrm{~cm}^{-1}$, with different intensities of the same band present in PEG 4000. Furthermore, these spectra showed different functional groups which make possible to see the chemical modification of PEG after the insertion of different groups in their chains. The results of the analysis confirm the morphological (by AFM and SEM images) and thermal modifications of the samples (by TG measurements). Based on the data presented, it is possible to state that the incorporation was successfully performed, as well as the polymer chain modifications. In addition, the modification of the polymer chain proves to be important to obtain satisfactory results over the unmodified polymer. Thus, modified polymers showed a well-satisfactory controlled release profile suggesting that these polymers have active pharmacological potential.

\section{ACKNOWLEDGEMENT}

Data generated in the Laboratory of Microscopy and Microanalyses of DEGEO / EM. Laboratory integrating RMIC, Microscopy and Microanalysis Network of Minas Gerais-FAPEMIG.

\section{REFERENCES}

1. Grassi, M.; Grassi, G.; Curr. Drug Delivery 2005, 2, 97.

2. Pillai, O.; Dhanikula, A. B.; Panchagnula, R.; Curr. Opin. Chem. Biol. 2001, 5, 439.

3. Frohoff-Hülsmann, M. A.; Lippold, B. C.; McGinity, J. W.; Int. J. Pharm. 1999, 177, 699.

4. Okarter, T. U.; Singla, K.; Drug Dev. Ind. Pharm. 2000, 26, 323.

5. Fu, Y.; Kao, W. J.; Pharm. Res. 2009, 26, 2115.

6. Inal, O.; Yapar, E. A.; Indian J. Pharm. Sci. 2013, 75, 700.

7. Borschiver, S.; Guimarães, M. J. O. C.; Dos Santos, T. N.; Da Silva, F. C.; Brum, F. C, P. R.; Polim.: Cienc. Tecnol. 2005, 15, 245.

8. Fulgêncio, G. O.; Saliba, J. B.; Fialho, S. L.; Júnior, A. S. C.; Rev. Bras. Oftalmol. 2013, 72, 232.

9. De Medeiros, J.; Kanis, L. A.; Rev. Bras. Famacogn. 2010, $20,796$.

10. Alessi, M. L.; Norman, A. I.; Knowlton, S. E.; Ho, D. L.; Greer, S. C.; Macromolecules 2005, 38, 9333.

11. Formariz, T. P.; Urban, M. C. C.; Júnior, A. A. S.; Gremião, M. P. D. G.; Oliveira, A. G.; Rev. Bras. Cienc. Farm. 2005, 41, 3.

12. Melo, N. F. S.; Grillo, R.; Rosa, A. H.; Fraceto, L. F.; Quim. Nova 2010, 33,1 .

13. Dos Santos, V. M. R.; Novack, K. M.; Silveira, B. M.; Rosa, J. S.; Macromol. Symp. 2014, 343, 78.

14. Dos Santos, V. M. R.; Monteiro, K. N.; De Sousa, D. V. M.; Oliveira, S. R.; Donnici, C. L.; Polim.: Cienc. Tecnol. 2015, 25, 19.

15. Dos Santos, V. M. R.; Monteiro, K. N.; Silveira, B. M.; Marcondes, H. C.; Macromol. Symp. 2018, 343, 7.

16. Azevedo, M. L. S.; Silveira, B. M.; Moneiro, K. N.; Dos Santos, V. M. R.; Macromol. Symp. 2018, 381, 1800145.

17. Kumbar, S. G.; Soppimath, K. S.; Aminabhavi, T. M.; J. Appl. Polym. Sci. 2002, 87, 1525 .

18. Rios, M.; J. Pharm. Technol. 2005, 29, 42. 